bluish from defective circulation, these splints have been worn daily for many months with much benefit, enabling patients to walk about who were previously quite helpless, and with the great additional advantage of keeping the limbs comfortably warm by means of the cotton-wool with which they are lined. Even when tightly laced, the presstre is so equably distributed that hardly any marks are found on the skin when the splints are removed at night, or for allowing the limbs to be rubbed or otherwise acted upon. Brighton.'

\section{STRANGULATED FEMORAL HERNIA OF FIVE DAYS' DURATION; OPERATION ; RECOVERY.}

BY W. A. ROSS, M.R.C.S., \&c.

THE chief features of this case seem to me to be the length of time-five days-that the hernia had been strangulated, also the age and weakly and emaciated condition of the patient at the time of operation, which I only performed as a last resource. She was for two hours under the influence of chloroform.

About 9 P.M. on Feb. 12th, 1879, I was called to see Mrs. S-, aged seventy. In answer to my inquiries I learnt that for more than twenty years she had been the subject of femoral hernia, which, for some reasons or other, she had never mentioned either to her husband or daughters. From time to time she had had attacks of colicky pains in the abdomen and constipation, which generally passed off in a few days, leaving her very weak. Sometimes she had been obliged to call in a medical man. When I saw her she had been suffering for four days previonsly with severe abdominal pain, and obstinate vomiting and constipation. She was somewhat emaciated, with pinched features and a hard and wiry pulse.

On examination I found a strangulated femoral hernia in the left groin, about the size of an egg, very painful, tense, and hard. I tried taxis and the warm bath with opium, but could not effect reduction. As the symptoms were not extremely urgent I administered a dose of morphia and left her.

The following morning, with the assistance of Messrs. Dustan and Seymour, A.M.D., the patient was put under the influence of chloroform, and all our efforts at reduction proving unavailing, I cut down on the sac in the usual way, and divided the stricture, and at the same time broke down some adhesions which had formed between the sac and the femoral ring. The contents of the sac, consisting of omentum in which was concealed a small knuckle of intestine, being in a tolerably healthy condition, were returned into the abdomen, and the wound closed with four sutures, and dressed with carbolic oil.

The further progress of the case was very satisfactory. In three weeks the wound was perfectly healed, with the exception of two small granulations where the sutures had been. Alderney.

\section{NOTE ON THE DANGER ATTENDING THE USE OF SALICYLIC ACID IN ACUTE RHEUMATISM.}

BY T. J. MACLAGAN, M.D.

1. IN acute rheumatism the heart is apt to be inflamed. Attention is usually concentrated on the membranes; but the muscular substance also suffers. When severe, myocarditis is apt to be fatal, and is frequently recognised in the post-mortem room. In a mild form it is, I believe, much more common than is usually supposed. It may exist independently of inflammation of the membranes. In all forms it produces softening and weakness of the muscular substance.

2. Salicylic acid, no matter whether given alone or in combination with soda, exercises a depressing action on the heart. This action is by no means general, and is probably due to some idiosyncrasy of the affected individuals.

3. If this depressing action be produced in one in whom the heart is physically sound, no great harm will be done.
With the omission of the drug the depression will soon pass off.

4. But if it be produced in one who is already the subject of rheumatic myocarditis (an ailment which is not easily recognised during life), and in whom therefore there exist softening and enfeeblement of the ventricular walls (for the left ventricle is the chief seat of such inflammation) the depression is likely to be alarming, and may be fatal.

To form an adequate estimate of the nature and extent of the dangers attendant on the administration of salicylic acid in acute rheumatism, we must recognise-first, the tendency of the rheumatic poison to produce inflammatory softening and weakness of the muscles of the heart; and, secondly, the tendency of salicylic acid to depress that organ. It is in the combination of these two that lies the danger of the drug.

It is in the absence of the tendency to produce such depression that lies the superiority of salicin over salicylic acid. Cadogan-place.

\section{dettirnor}

\section{HOSPITAL PRACTICE, BRITISH AND FOREIGN.}

Nulla autem est alia pro certo noscendi via, nisi quamplurimas et morborum et dissectionum historias, tum aliorum, tum proprias collectas habere, et inter se comparare.-Morgagni De Sed. et Caus, Morb., lib. iv. Procmium.

\section{GUY'S HOSPITAL.}

SURGICAL CASES ILLUSTRATING WOUND TREATMENT AND REPAIR.

(Under the care of Mr. BRYANT.)

Cancer of the Breast; Excision; Primary Union of Wound. (From notes by Mr. Dashwood.)-Mary Ann Waged fifty, was admitted into Lydia ward on July 16th, 1879. She was a married woman, but had had no children. Her menses had always been regular. About a month before she noticed a little milky discharge from the left nipple. She had occasional shooting pains, and in a week or two she noticed the nipple was retracted, and that there was a small swelling at the lower part of the left breast. The swelling slightly increased in size.

On admission she was a healthy-looking woman. She had two scars on the upper part of the left breast caused by a burn in childhood. At the lower part of the left breast, behind the nipple, was a hard, nodulated, movable tumour, about the size of a pigeon's egg. The skin was normal, and movable over the tumour. There were no enlarged glands, and no pain. The case was supposed to be one of cancer.

On July 22nd, while under chloroform, an exploratory cut was made, but no pus escaped. Two semicircular incisions were then made, enclosing the nipple, and directed obliquely downwards and inwards. The whole breast was removed. Several arteries were twisted, but there was not much hæmorrhage. The wound was washed with iodine and water, and the edges brought together with silk sutures and waterproof strapping; it was dressed with oil of turpentine. The wound healed by primary union, and she left on Aug. 14th.

Temperature Chart. - On July 22nd the temperature was $978^{\circ}$; after 8 P.M., $100 \cdot 2^{\circ}$. 23rd : Morning, $99^{\circ} 8^{\circ}$; evening, $98 \cdot 4^{\circ}$. 24th : Morning, $97.8^{\circ}$; evening, 100 $2^{\circ}$. 25th : Morning, $1006^{\circ}$; evening, $98^{\circ}$. From this time the temperature never rose more than one degree above normal.

Adenome of Breast; Excision; Repair by Primary Union. (From notes taken by Mr. Dashwood.)-Leah $\mathrm{S}-$ aged twenty-six, was admitted into Lydia ward on July 16th, 1879. She was a single woman, and had always enjoyed good health. About a year before she noticed a hard swelling upon the upper part of the right breast. Though it had not apparently increased in size, the skin over it turned blue, which caused her to apply at the hospital. The menses had been regular.

On admission there was a hard tumour, about the size of a hazel nut. The surface was flat, but the margins were nodulur. The tumour was freely movable, and the skin 